\title{
RIGHT, LEFT, HIGH, LOW NARRATIVE STRATEGIES FOR NON- LINEAR STORYTELLING
}

\author{
SYLKE RENE MEYER \\ PROFESSOR AND ASSOCIATE DIRECTOR, MFA PROGRAM \\ IN CREATIVE WRITING AND LITERARY ARTS AT \\ CALIFORNIA STATE UNIVERSITY, LOS ANGELES \\ POST@SYLKE-RENE-MEYER.COM
}

\begin{abstract}
.
Based on studies of affect, and on theoretical works concerning spatial semantics by Yuri Lotman, Mikhail Bakhtin, Michel Foucault and others, spatial story design provides a seven step algorithm of story development for interactive audio-visual narrative. Following spatial semantics and its application in interactive storytelling, the author no longer creates the protagonist, his or her want or need, nor controls the story arc. Instead, spatial story design allows the author(s) to make the formative creative decisions by designing a narrative space, and spatial dynamics that then translate into user generated storylines. Spatial story design serves as a framework for interdisciplinary collaborations, and can be used to not only create interactive digital narrative but also screenplays, improvisational theatre, $360^{\circ}$ films, and walk-in story world experiences for a number of users in either live or holographic virtual reality spaces. Spatial story design could inspire creators of interactive narrative, storytellers in time-based media, and possibly also technology developers for authoring tools.
\end{abstract}

Keywords: non-linear storytelling; environmental storytelling; spatial story design; affect theory - screenwriting; digital filmmaking; improvisational theatre; Mikhail Bahktin - Yuri Lotman; Michel Foucault. 


\section{Premise and Promise}

Today, interactive user-oriented narrative is overtaking the story structures linked to the linear narrative of time. Unlike time-based media which are often single-authored, and presented to its audience, digital narrative evolves through use. The user, unlike the audience, co-creates the story while playing it. This most recent manifestation of storytelling challenges time-based linear storytellers, as well as spatially oriented narrative designers. In this context, the cross pollination between today's media may lead to a different kind of storytelling, as film in the beginning of the $20^{\text {th }}$ century influenced storytelling in all other media. Following Marie-Laure Ryan, and others, I contend that "the choice of a certain medium, e.g. computer game vs. film, modifies the way in which the story is shaped, presented and received" (Ryan, 2003). Interactive digital narrative may be seen as the medium of the 21 th century, and probably mark the end of time, because it is no longer based on time, as time-based audio visual media is, but on space, and therefore correlates with our current world view of "living in the epoch of space" described by Michel Foucault in his essay "Of Other Spaces: Utopias and Heterotopias. Taking its cue also from Adorno and Marshall McLuhan, that every social contradiction returns as a formal problem in art, and that every revolution employs the newest medium, spatial story design may provide the dramaturgy for stories that respond to the social contradictions and collective neuroses of our time, and to the message of a digital medium that is inclusive, democratic, and user-oriented.

Let me begin by clarifying my understanding of interactive storytelling, and the questions I try to answer. The probably strongest presence of interactive storytelling can be found in narrative games, where interactivity can take a wide range, from hardly any formative presence of interactivity to unlimited participation. Games can be classified through the relationship between the game story and the player story. The game story comes from linear storytelling is based on questions concerning the protagonist's motivation, like super Mario has to free princess peach. The player story consists of verbs concerning the player's actions. It is the actual experience the player makes while playing: excitement, stress, joy while jumping, collecting, running, shooting etc. In a broader sense, the player story generates its own narrative while playing. The player story is always interactive, enabled and limited by the game mechanics, the code. The game story is authored. Interactivity is based and limited to the number of storylines preconceived by an author that allow the user to make choices. The more story and game overlap, the more interactive storytelling we actually create. Dragon's Lair (1983) for example consists of practically $99 \%$ story and offers hardly any interactivity. If you don't follow the written and predefined story, you'll never see a dragon. Many of the current developments in narrative games chose this format, often within a cross-medial story world. For example The Walking Dead (2010-present) works as a TV series, as well as a single story game allowing the user to enjoy an immersive experience that may eventually replace cinematic experiences, yet not a lot of interactivity. Heavy Rain (2010) has an extended interactive matrix, using a dynamic narrative (an Al narrator) to while games like Call of Duty (2003-present), has hardly any story at all, and allows for a maximum of interactivity.

Interactive storytelling follows in principle one of these three models: the tree structure, the directed network structure, and the open world model. Although multi-linear, they first two models are linear, and offer only limited interactivity, and limited user-generated narrative. Linear story models like the 'hero's journey' have been employed to only create a predictable story arc based on narrative clichés already present at the users narrative vocabulary. As a result, multi-linear story models represent one of the problems in interactive digital storytelling that manifests itself in the debate between ludologists and narratologists, and the question of whether or not interactivity is actually the opposite of storytelling, (the problem of interactivity versus plot), in which interactivity 
is almost the opposite of narrative (Adams, 1999; Costikyan, 2000).

A maximum of interactivity presupposes a non-linear, open story world where the visitor or user navigates and operates freely. Yet here, story models like the P.I.N.G. model (Passive-Interactive Narrative-Game model) struggle with the lack of narrative control (here with the game Aporia) over the narrative experience that the user makes. "In general too few (20\%) participants understood the story in Aporia. The interaction with key objects seemed to steal the focus from the narrative and took most of the participants' focus, also when describing the narrative" (Bevensee et al., 2012).

Alternatively, my concept of spatial story design privileges space over time and usership over authorship, yet at the same time, it gives the author some creative control over the narrative trajectory in space. In open world story design, every visitor or user will experience a different story. What we - as storytellers- can do is to create a narrative corridor, a zone of likelihood and probability. As storytellers, we may have to embrace the idea that we no longer write ONE Story, but design a narrative corridor for potential stories. In probability theory in mathematics as well as in interactive story design, we cannot predict the user's behavior with certainty, but we can control certain narrative factors to estimate the prob- able behavior of the user in an interactive narrative environment. In non-linear open story worlds, we cannot design a protagonist, his want or need, no character arc, no turning points - but have to invent a different dramaturgy.

The seven step algorithm which I outline is a space-based tool for linear and non-linear storytelling: user-generated narrative, interactive digital storytelling, screenwriting, $360^{\circ}$ film making, or any audience-engaging narrative practice that relates to space. It is a basic narrative tool that allows the author to control-to some extent-the space, the story, and the objects that lead to objectives. Referring to Henry Jenkins (2004) and his terminology of "environmental storytelling," (idem) the seven step spatial story design strategy may work in every aspect of environmental storytelling: with evoked narratives that have the ability to enhance an already existing one, with enacted narratives that provide narrative elements built up around characters, with embedded narratives where the object and the staging enables the plot, and with emergent narratives where the users construct their own narrative in the story space.

Spatial story design is a narrative strategy that draws from a theory of narrative space, which emerged from the outer frontiers of an empire; marginalized, forbidden, almost secret, it was conceived in provinces of the former Soviet Union.
The concepts of Yuri Lotman and Mikhail Bakhtin laid the ground work for an entirely new philosophical approach that became eminent in the late 1980s under the label of the 'spatial turn,' and include, amongst others, the works of Michel Foucault, Julia Kristeva, Susan Stanford Friedman, Gaston Bachelard, Michel de Certeau, and Henri Lefevbre. At this point, many works on spatiality could not been taken adequately into account, and the following concept only outlines the basic idea of spatial story design.

\section{Spatial Semantics 2.1 Yuri Lotman and the Semiosphere}

Yuri Lotman was born in 1922, and graduated at the age of only 17 years, and with excellent grades from the University of Leningrad. Being Jewish however, the high potential youth was not allowed to proceed with his doctorate at the heart of the empire, and instead had to go to Tartu, a small town in Estonia where he stayed for the rest of his life. Therefore his theoretical body of work is referred to as the "Tartu-Moscow Semiotic School."

In Lotman's analysis of narrative texts, the temporal structure of the story is not in the foreground, but the spatial organization, the "semiosphere." According to Lotman (1990), a semiosphere (from 
the Greek semio for sign, and sphere for space) can be a concrete space with a real geographical topology, such as St. Petersburg, but it can also be a metaphorical space, whose topology consists of the characters of a "plot space," such as the main characters of a myth, the hero, the opponent, the helper, father, mother, son, daughter, etc.

In Lotman's terminology, cultures, semiotic spaces, and semiospheres share the same topological characteristics. In other words, cultures, semiotic spaces, and semiospheres have centers, peripheries, insides and outsides, and boundaries. A (semantic) room is defined in contrast to another room, by its differences, and the border between these two spatial areas is particularly visible. A semiosphere thus is surrounded by a boundary.

For Lotman, the border is the most important topological feature, that parts the text (or its overall semantic space) into (at least) two disjunct areas, a term he borrowed from set theory where disjunct spaces are defined as ' $M$ ' and 'Not-M,' meaning the areas are divided into completely separated parts or pieces.

Lotman contends that these areas differ at various levels: first, they are topologically in opposition - for example, one space is high, the other low. Second, spaces are defined not only by size and location, but also by content, such as characters, states, and functions. For this content, Lotman introduced the term 'semantic properties' of space. Third, to establish a border between two rooms or two areas, each room has to be assigned with a different meaning. For example, one room is good, the other is evil. The semantically loaded topological order then translates into topographical contrasts within the world represented for example a city vs. mountains (the city being low and evil, and the mountains being high and good).

\subsection{Mikhail Bakhtin and Chronotope}

The second outsider of spatial narratology in the Soviet Union is Mikhail Bakhtin, who was banished to Kazakhstan by Stalin in 1929, and worked as a teacher intermittently until his retirement in 1961. Bakhtin created his main body of work in the 1920s and 1930s, but became more widely known only in the 1960s, mainly through Julia Kristeva and her translation of his works into French. Bakhtin left us an abundance of discourse material from which I will emphasize only one aspect at this point: his concept of the chronotope, translating from the Greek chronos for time and topos for space.

According to Bakhtin, the relationship between time and space constitutes the possibility of actions of the characters.
Space organizes the chronological order of the narrative events, and time fills the space with meaning. In other words, the chronotope forms the dynamics of the story world.

Often, time becomes more important in a confined space; and if time is less important, the room expands. In a road movie, we expand space and travel long distances, while the duration of the trip often plays only a subordinate role. In prison films, time plays a prominent role in the compressed space of the prison cell.

Game designers are quite aware of this property of the chronotope, as the author of a game has more control over the user in confined spaces, because the possibilities of movement are limited for the player. In contrast, a player can walk endlessly through a vast, or open source narrative game landscape. In narrative games, the author controls time mostly by controlling space. Therefore, temporal markers are rare in narrative games: we mark time often with the question, "where" we are in the game. It is a question that asks for time and space at the same time, and that is often answered only by space. In response, the player may tell us that she is in the water dungeon and this is how we know on what level of the game she is, how temporally advanced, and how spatially located.

Bakhtin assigns a special symbolic message to spaces such as the threshold, 
the gate (meeting, farewell), the court (determination, accuracy, judgment), the path (life, travel, maturity). Other examples are the exile, the landscape, the river, the island, the ship, the lighthouse, the city, the fortress, the house, the stage, etc. that may carry a variety of symbolic messages depending on their context. Also, for example, the places of childhood-like the attic of the family house where a child has found magical things-is a chronotope (Bakhtin, 1981; Todorov, 1984). Chronotopes announce through convention, and their symbolic connotation is a narrative planting, a certain course of action that is about to come. Settings also indicate a linear narrative that has already taken place, like in the example above: somebody must have locked the door. Thus, in space we read the past, the present, and a possible outcome.

\subsection{Affect-Emotion-Feeling}

The player (the subject) that enters the story world responds to his or her environment, and this is how he or she will emotionally respond, make decisions, and consequently act. In this way, the player or user responses with judgment, and object placing in this sense can influence his or her process of decision making. However, every subject, every player, has a unique consciousness and set of personal experiences, therefore no one player will have the same rela- tionship with another entity that exists outside of him or herself.

Although the terms emotion, feeling and affect are routinely used interchangeably, it is important not to confuse them (In detail, Heise, 2002). In the definition of Brian Massumi (1987), feelings are personal and biographical, emotions are social, and affects are pre-personal. Affects in this definition are visceral and not informed by culture. They function as a basic physical response, much like instincts. For example, the object 'fast approaching tiger' will trigger an affect that is most likely related to death and fear of deadly violence.

Therefore, object-based affect-control is an important aspect of story design. These affective practices are triggered in familiar ways, and with familiar patterns. Affect can also be seen partially as, any evaluative (positive or negative) orientation towards an object. Behavior depends on personal, cultural, or visceral affects and on the surrounding objects and environment. In the words of psychologist and system theorist Kurt Lewin, behavior is a function of personality and environment $(B=f(P, E))$. So if we change somebody's environment, we also change somebody's behavior. This principle is also known in public communication as choice architecture, and refers to our ability to structure the physical space around us to prime good choices. For example in a grocery store products on shelves at eye level get purchased more than those down by the floor, or the Massachusetts General Hospital in Boston, where they discovered that they could instantly increase the amount of water people drank and decrease the amount of soda they drank simply by rearranging the way drinks were displayed in the cafeteria. Same applies, for the digital environment. There are a wide range of digital triggers that prompt our behavior. When Facebook notifies you of a new action, you're prompted to log back on. When someone emails you, you are prompted to respond. These digital triggers are simple ways of building habit-forming behaviors in online products and services. In many cases, these digital triggers become distractions that take you away from the work and habits that are actually important to you - but they can also be used to instigate a certain behavior of a user in a VR experience.

There are particular affect-laden, social phenomena that can be usefully investigated through storytelling. For example, institutionalized moments of celebration (New Year), grief (funeral services), joy in belonging (sport fans in a stadium) etc. In certain spaces, the subject-object-relationship may be so strongly predefined that the players' decision making corridor is extremely narrow. Here, the author or story designer holds a maximum of narrative control over the affect-informed behavior of the 
user. These spaces are quite often chronotopical as described by Bakhtin, and have been analyzed in depth by Michel Foucault in his concept of "heterotopias."

\subsection{Michel Foucault and Heterotopia}

In most heterotopian spaces, the subject is forced to submit to the order of things. Foucault introduced the term to mainly reveal power structures but the terminology also serves as an useful narrative tool, and since stories (myth) reflect power relations, literary settings are often-not coincidentally-heterotopias. Additionally, in narrative design, the author may create his or her own order of things, his or her own heteropias, and thereby not only offers an alternative worldview, but also gains some control over the user's affects.

Heterotopias are spaces that reflect social conditions in a special way by representing, negating or reversing social relations. Examples of heterotopias are juvenile, retirement, and nursing homes; psychiatric hospitals; prisons; colleges of the 19th century; barracks; cemeteries; cinemas and theaters; gardens; museums; libraries; fairgrounds; holiday villages; ritual and non-ritual purification sites; guest houses; brothels; and colonies. Heterotopias are places where a behavior deviant from the prevailing norm is ritualized and localized. To understand what deviant behavior, what "the other" means, Foucault returns repeatedly to the subject of travel as the symbol of journey, of exploration, and discovery. Like a story that takes the recipient or user on a journey, Foucault (1986) contends that the place of hopes and desires has always been the ship: a "place without a place, " a self-contained room on the high seas. Foucault emphasizes that from the Renaissance to present time, the ship not only serves as an important tool for economic development, but also as the greatest arsenal of imagination: "The ship is the heterotopia par excellence. In civilizations without boats, dreams dry up" (idem).

Concerning the key role of time in this regard, Foucault describes two forms of heterotopias: those in which time is accumulated endlessly, piled up, and pressed in books or pictures to be showcased and archived in libraries and museums, and those in which time is extremely limited, and dissolves within a few hours or days, as with festivals or fairs.

Furthermore, heterotopias are always bound to a system of openings and closings to prevent easy exit and entrance. Every entry and exit is subjected to a certain incoming and outgoing ritual. These rituals may manifest itself in complex purification rituals such as a academic entrance examinations, or in a relatively mundane activity like paying your entrance fee at the cinema. The examples show how different these rituals can be, and to what degree the opening or closing to the outside can vary - in cinema everyone buying a ticket is admitted, in the university, however, the visitor must first acquire specific knowledge before being allowed to enter the place. In addition, not everybody entering a room is participating voluntarily in the heterotopia. For example, entering a prison for prisoners is a highly involuntary form of participation; on the other hand, a visitor walking into the area of the prison remains largely excluded from its heterotopic structures.

\section{Spatial Story Design 3.1 Defining Space}

Time-based narratives have a beginning, middle, and end. In contrast, in space-based storytelling, the story unfolds while the user navigates through space, interacting with objects present and possibly with other users. It has no determined beginning, and no specific course. In linear, time-based storytelling, a writer usually starts with a character and an action; in space-based storytelling, a narrative designer creates a space and objects. Following spatial semantics and its application in interactive storytelling, the author no longer creates the protagonist, his or her want or need, and does not control the story arc. 
Defining a space is one of the most important creative decisions a narrative designer must make. The starting point is always a specific narrative space that contains per se a prolepsis (a narrative planting), and a number of suggested dynamics. The space generates the dramatic or narrative question, like a room with a locked door, which generates the question of whether or not the characters or players will be able to open the door and to find out what's behind it.

In a next step, the space will be filled with objects. Objects are far from arbitrary but influence how a player will navigate the space. Objects in this sense can be physical things but also other characters. Here an object is defined as something observed, while a subject is an observer.

\subsection{Border Crossing}

In Yuri Lotman's terminology, simply relocating a hero within the assigned space is not an event, or in other words: it is not a dramatic action.

"What then is an event as a unit of plot construction? An event in a text is the shifting of a persona across the borders of a semantic field." (Lotman, 1971, p. 233)
Here the term event corresponds with Aristotle's perepeteia (turning point). To Lotman, an event presupposes a couple of binary oppositions: a norm, and a non-norm. Here, the (semiotic) border is a key concept in Lotman's thinking. It doesn't matter if the division falls into friends and enemies, living and dead, rich and poor, or other. What is important is something else: the boundary that divides the space must seem insurmountable.

Based on this this logic, another basic assumption implies. As explained earlier, in set theory, disjunct spaces are defined as ' $M$ ' and 'Not-M'. 'M' would be something like: all motorists drive on the right side of the road. All scientists argue rationally. All Germans are diligent. Here, the definition of ' $M$ ' formulates a norm. Lotman also draws from this context in his concept of border control. In his view, an event-creating border crossing also always violates a norm. Romeo and Juliet cross the physical border from one enemy house to the other, but even more so, they violate the fraternization ban of their houses. An event therefore questions the validity of a set order. If this order is represented by a topographic boundary, the event appears as a border crossing; if the given order manifests itself as a norm or rule, the event appears as the violation of that rule, as an incident departing significantly from the norm, or in Foucault's terminology, is deviant. Therefore, in order to create an event, one needs to clarify the standard, the norm, first.

Lotman gives the example of a couple arguing about art. She hates abstract painting, he loves it. In his example, the aggravated couple goes to the police to report the other. The policeman obviously sends them home. No norm-as far as he is concerned-has been violated. Hating or loving abstract art is not a crime. However, at home, the couple decides to get a divorce - the falling out over art has shaken the very foundation of their marriage. Therefore, not every room change is an event, just as in time-based linear storytelling, not every activity is dramatic action, and not every story step is a turning point.

\subsection{Characters \&Action}

According to Lotman, rooms can be inhabited by mobile and immobile figures. The immobile figure classifies and defines the space. For the immobile character, a border crossing is prohibited. The mobile character, the hero, is a character with a special predisposition that allows him or her to cross the border between the two disjunct spaces.

As an example, Lotman points to the hero of fairy tale, who penetrates the enchanted forest and frees the princess from the clutches of the dragon. The hero leaves the daytime world of his 
village and crosses the border into the night world of the forest. The forest and the village are disjunct to one another, they don't share a single property, and no one in the village dares to enter the forest- but the hero.

Space in this sense is not necessarily only seen topologically, but may also be characterized semantically, i.e. rooms with different meanings can be found in one physical space. Lotman calls an event "restitutive" if the hero tries and fails, and "revolutionary" if the hero tries and succeeds, which relates to the dramatic concepts of tragedy (trying and dying) and comedy (trying and succeeding) in the Aristotelian sense.

The mobile character leaves the room, or at least he or she tries. On his or her way to overcome the border, the hero faces obstacles. The obstacles can be so substantial that it is impossible for the hero to cross the border. The hero may die (physically or symbolically) in the attempt to make it from the original field into the anti field.

If the hero manages to cross the border, she or he has to merge with the new room, and will now become an immobile figure. The transition from a mobile to an immobile characters marks the end of the story. If he or she does not merge with the new space, the story has not come to an end yet, and border crossings will have to continue until the mo- bile character has become an immobile character.

Characters in rooms do not perform aimless movements. Lotman describes rooms, or spaces, as hierarchical, and distinguishes certain elements as the highest-ranking. High ranking elements can assume the function of a topographical property. Examples of topographical extreme points are main streets, town squares, towers, mountain peaks, canyons, the abyss, but also interior elements like the TV, the fireplace, and the dinner table. All these examples serve as power centers of the room.

Taking its cues from Lotman, narratologist Karl N. Renner suggested that all character movements within the hierarchal space are oriented towards the to "extreme point." Extreme points are high-ranking elements that set the rules of that space. All other elements gravitate towards the extreme point (Renner, 2004).

Non-topographical elements may also structure the space, and serve as extreme points. These are the extreme points of social space, for example, the position of a head of the family.

When designing or analyzing space, the extreme point is based on the question of who or what owns or rules the space. Then, two complementary patterns of movement can be identified: in one case, the direction of the character's movement changes once he or she has reached the extreme point, and the character leaves the space into which he or she has entered. The extreme point here marks a turning point in the story. For example, the character is having an argument with an abusive boss, quits the job, exits, and slams the door. In the second case, the movement of the character comes to a standstill when reaching the extreme point, and the character assumes the status and nature of this space (the hero kills the evil magician, and takes his throne). Here, the extreme point is the end point of the story.

\subsection{The Seven Step Algorithm of Spatial Story Design}

Story design based on spatial semantics takes the following steps:

1. Authorship begins with the design of a specific setting. How does the author characterize the semantic space, topology, semantic properties, meaning, topography - intellectually and aesthetically? What chronotope or heterotopia forms the setting? What are the norms and objects of this story world? What is the order of things?

2. The author or authors place specific objects and subjects at the place, and hereby gain some control over the affects of the user, and the promised narrative, inherent to the symbolic 
language of the space. In this context, the ideas and insights developed in the field of affect theory will prove to be essential, to help to understand how affect and emotion of the user can be directed by and through object making and object interaction.

3. The author controls and designs entrances and exits. The authors design the rituals performed to allow a character or player to exit, or enter.

4. The authors create immobile characters, and room for mobile characters.

5. The authors create norms, boundaries, and extreme points.

6. The authors design obstacles - topological and social.

7. Based on the properties and characteristics of the foundational space, the authors create disjunct subspaces and anti fields, potentially in indefinite numbers, and potentially in collaboration with the users, like in reality based environments, or massively multiplayer online role-playing games (MMORPGs).

\section{Usership and Conclusion}

The seven step spatial design process privileges co-authorship over single authorship, can be used to create $360^{\circ}$ narrative, walk-in story world experiences for a number of users in either live or holographic virtual reality spaces, and may also serve as a framework for interdisciplinary collaborations.
Digital filmmaking today doesn't comply with the traditional linear work flow of story development, preproduction, postproduction, and distribution, but rather follows the iterative design process. Consequently, the former division of labor between the departments, especially the line between writing the screenplay and realizing the screenplay, has blurred. ${ }^{1}$ Screenplay development and film development have merged, and involve nearly every department. Spatial story design may close the common gap between writers whose thinking is quite often informed by the linearity and chronology of a written text, and their collaborating creators who think predominately spatially. In film production for example, where production designers design the sets, the DOP assembles the room through different camera angles, the director navigates the characters through space, the editors re-assemble the spatial aspects, and so on, all departments may contribute with their specific areas of spatial competence to the story development. Story development would then include every department from the beginning, and interactive narrative interventions could also include the user, formerly known as the audience member.

In $360^{\circ}$ film making, the viewer cannot interact with the subjects and objects of the story world. Most experiments in $360^{\circ}$ fiction narrative film that aim to create an immerse experience, fail to over- come the narrative oddities of a forced POV perspective that explains why the viewer is barred from (inter) acting with other characters - such as being chained, in a coma, or hidden in a closet - for the entire film. The misunderstanding I believe lies in the assumption that an immersive $360^{\circ}$ narrative visual experience has to be also an experience of dramatic identification of the viewer with and as the protagonist of the story. Instead, $360^{\circ}$ narrative visuals work best for an observer, a non-identified viewer which is maybe why $360^{\circ}$ films are most successful in non-fiction storytelling like documentaries, concerts, or sports events. Here, the concept of spatial story design can be used as dramaturgy to structure real live events. Instead of arbitrary recording, the seven step algorithm can be used to select and design place and object, and to analyze, emphasize, and utilize its semantic properties. Intelligent film design allows the filmmaker to respond to the way the user navigates and perceives the story world. The viewing devices record and remember what the viewer has already seen, and now redirect the viewer's attention through audio cues, audio volumes, object placing, and moveable character action in relationship to the extreme point.

Spatial story design may also help to design a narrative experience in VR environments, and to create holodeck cyberdrama as described by Janet Murray (1998): "A world we can enter, 
manipulate, and observe in process. We might therefore expect the virtuosos of cyberdrama to create simulated environments that capture behavioral patterns and patterns of interrelationships with a new clarity." In cyberdrama, the heterotopian laws of everyday life apply. The authors of cyberdrama will create a specific order of things, and have full control over the spatial design, the social order, the exit and entrance rituals, and the placing of affect-laden objects. The authors may also create anti-fields for other users to enter the cyberdramatic holodeck from the (semantically speaking) opposite direction that are designed to create conflict - the heart of drama. Just as Hamlet makes decisions, the user will make decisions, within the restrictions created for the narrative semantic field, and be able to "enact the contemporary human struggle to both affirm and transcend our own limited point of view" as envisioned by Janet Murray.

\section{References}

Adams, E. (1999). Three Problems For Interactive Storytellers. Gamasutra.com, http:// www.gamasutra.com/view/feature/3414/the_designers_note\%20book_three_.php (Accessed on August 2017).

Bakhtin, M. (1981). Forms of Time and the Chronotope in the Novel. In M. Holquist (ed). The Dialogic Imagination: Four Essays. Austin: University of Texas Press, Slavic Series.

Bevensee, S. H., Dahlsgaard Boisen, K. A., Olsen, M. P., Schoenau-Fog, H., \& Bruni, L. E. (2012). Project Aporia - An Exploration of Narrative Understanding of Environmental Storytelling in an Open World Scenario. In D. Oyarzun, F. Peinado, R. M. Young, A. Elizalde, \& G. Méndez (Eds.), Interactive Storytelling: 5th International Conference, ICIDS 2012, San Sebastián, Spain, November 12-15, 2012. Proceedings (pp. 96-101). Berlin, Heidelberg: Springer Berlin Heidelberg. Retrieved from https://doi. org/10.1007/978-3-642-34851-8_9.

Costikyan, G. (2000). Where Stories End and Games Begin. Game Developer. September 2000, 44-53.

Davis, N., A. Zook, B. O'Neill, B. Headrick, M. Riedl, A. Grosz, and M. Nitsche. (2013). Creativity Support for Novice Digital Filmmaking, CHI 2013: Changing Perspectives, Paris, France. http://homes.Imc.gatech.edu/ nitsche/download/Davis_CreativitySupport_13.pdf (Accessed on August 2017).

Eskelinen, M. (2001). The Gaming Situation. Games Studies. The International Journal of Computer Game Research. 1:1. July 2001. http://www.gamestudies.org/0101/eskelinen/ (Accessed on August 2017).

Foucault, M. (1986). Des Espaces Autres (Of Other Spaces: Utopias and Heterotopias), In Architecture, Mouvement, Continuité, no. 5, October 1984: 46-49; translated by Jay Miskowiec, In Diacritics 16, no. 1 pg.9. Spring, 1986.

Heise, D. R. (2002). Understanding Social Interaction With Affect Control Theory. In ,J. Berger and M. Zelditch (Eds.) New Directions in Sociological Theory. Chapter 2. Boulder, CO: Rowman and Littlefield. 
Jenkins, H. (2004). Game Design as Narrative Architecture. In Wardrip-Fruin, N., Harrigan, P. (Eds.). First Person: New Media as Story, Performance, and Game, pp. 118130. Cambridge: MIT Press.

Juul, J. (2001). A Clash Between Games and Narrative. Version 0.99, April $17^{\text {th }}$. https://www.jesperjuul.net/thesis/ (Accessed on August 2017).

Juul, J. (2001). Games Telling Stories?, Game Studies, Games Studies. The International Journal of Computer Game Research. 1:1. July 2001. http://www.gamestudies.org/0101/juul-gts/ (Accessed on August 2017).

Lotman, Y. (1990). Universe of the Mind: A Semiotic Theory of Culture. Shukman A. (Trans.). Bloomington: Indiana University Press.

Lotman, Y. (1971,[1977]). The Structure of the Artistic Text. translated from the Russian by Ronald Vroon, University of Michigan.

Massumi, B. (1987). Foreword. In Deleuze, G., \& Guattari, F. (1987). A Thousand Plateaus. Minneapolis MN: University of Minnesota Press.

Murray, J. (1998). Hamlet on the Holodeck. The Future of Narrative in Cyberspace, part II. ebr7 image+narrative part two. Summer 1998. http://www.altx.com/ebr/ ebr7/7murray/7mur2.htm (Accessed on August 2017).

Renner K. N. (2004). Grenze und Ereignis, Weiterführende Überlegungen zum Ereigniskonzept von Jurij M. Lotman. G. Frank, W. Lukas (Hgg.). Norm-Grenze - Abweichung. Kultursemiotische Studien zu Literatur, Medien und Wirtschaft. Festschrift für Michael Titzmann, pp. 357-381, Passau: Verlag Karl Stutz

Ryan, M-L. (2003). On defining narrative media. Image \& Narrative. Online Magazine of the Visual Narrative. 6. Medium Theory. January 2003. http://www.imageandnarrative.be/inarchive/mediumtheory/marielaureryan.htm (Accessed on August 2017).

Todorov, T. (1984). Mikhail Bakhtin: The dialogical principle. Manchester: University of Minnesota Press.

\section{Endnotes}

1 A process also described in the analysis of machinima as digital filmmaking by Davis et al. (2013). 
RIGHT, LEFT, HIGH, LOW NARRATIVE STRATEGIES FOR NON-LINEAR STORYTELLING SYLKE RENE MEYER

Call Of Duty (2003-present). Activision.

Dragon's Lair (1983). Cinematronics,

Heavy Rain (2010). Sony Computer Entertainment.

Walking Dead (2010-present). TV Series: AMC. Game: Telltale 2012-present. 